NASA Technical Memorandum- 103655

\title{
Silicon Carbide, a Semiconductor for Space Power Electronics
}

J. Anthony Powell and Lawrence G. Matus

Lewis Research Center

Cleveland, Ohio

Prepared for the

8th Symposium on Space Nuclear Power Systems cosponsored by the University of New Mexico, National Aeronautics and Space Administration, Strategic Defense Initiative Organization, U.S. Department of Energy, and U.S. Air Force

Albuquerque, New Mexico, January 6-10, 1991

\section{MNSA}

(NA5A-TM-103055) SILICON CARBIDE, A

SFMICONDUCTOR FOR SPACE POWER ELECTRONICS

(NASA) $8 \mathrm{P}$

CSCL $20 \mathrm{~L}$

$N 91-14850$ 


\title{
SILICON CARBIDE, A SEMICONDUCTOR
} FOR SPACE POWER ELECTRONICS

\author{
J. Anthony Powell and Lawrence G. Matus \\ NASA Lewis Research Center \\ 21000 Brookpark Road \\ Cleveland, OH 44135
}

\begin{abstract}
After many years of promise as a high temperature semiconductor, silicon carbide (SiC) is finally emerging as a useful electronic material. Recent significant progress that has led to this emergence has been in the areas of crystal growth and device fabrication technology. High quality single-crystal SiC wafers, up to $25 \mathrm{~mm}$ in diameter, can now be produced routinely from boules grown by a high temperature $(2700 \mathrm{~K}$ ) sublimation process. Device fabrication processes, including chemical vapor deposition (CVD), in situ doping during CVD, reactive ion etching, oxidation, metallization, etc. have been used to fabricate $p-n$ junction diodes and MOSFETs. The diode was operated to $870 \mathrm{~K}$ and the MOSFET to $770 \mathrm{~K}$.
\end{abstract}

\section{INTRODUCTION}

In recent years, there has been a growing need for electronic components capable of operating at high temperatures for extended perlods of time. The desired operating temperature in some applications approaches $900 \mathrm{~K}$, which is well beyond the capability of currently available semiconductor devices. Silicon carbide possesses unique properties which make it suitable for such applications (Harris and Yang 1989). Because of these properties, NASA Lewis is developing a new family of semiconductor devices based on SiC for aerospace propulsion and power applications. This paper reviews pertinent sic properties and describes recent advances in SiC semiconductor technology at NASA Lewis and elsewhere.

\section{PROPERTIES}

An unusual aspect of $\mathrm{SiC}$ is that its crystal structure exhibits a form of one-dimensional polymorphism called polytypism. The many polytypes of SiC differ from one another only in the stacking sequence of double layers of $s i$ and $C$ atoms. This paper considers only the two most common polytypes, a cubic structure known as $3 \mathrm{C}-\mathrm{SiC}$ or $\mathrm{B}-\mathrm{SiC}$, and a hexagonal structure known as $6 \mathrm{H}-\mathrm{SiC}$.

An appreciation of the potential of sic can be gained by examining rable 1 , which is a comparison of its properties with diamond and GaP (two other contenders for high temperature semiconductor applications) and the two most common commercially available semiconductors, si and GaAs. In the sic column of the table, the quantities in parenthesis pertain to $6 \mathrm{H}$ sic. The maximum operating temperature was calculated relative to that of $\mathrm{Si}$ by assuming a maximum for $\mathrm{si}$ of $600 \mathrm{~K}$ and multiplying this temperature by the ratio of bandgaps. The maximum for diamond is imposed by a phase change.

silicon carbide does not melt at any reasonable pressure, but does sublime at temperatures greater than $2100 \mathrm{~K}$. Below $1800 \mathrm{~K}$, its physical stability is 
TASLE 1. Comporison of Semiconductors

\begin{tabular}{|c|c|c|c|c|c|}
\hline Property & $\mathrm{Si}$ & Gots & Gop & $\begin{array}{c}\beta-\operatorname{SiC} \\
(6+\operatorname{SiC})\end{array}$ & Diomond \\
\hline $\begin{array}{l}\text { Bendgoo (ev) } \\
\text { ol } 300 \mathrm{~K}\end{array}$ & 1.1 & 1.4 & 2.3 & $\begin{array}{r}2.2 \\
(2.9) \\
\end{array}$ & 5.5 \\
\hline $\begin{array}{l}\text { Moximum operoting } \\
\text { temperoture }(K)\end{array}$ & 600 & 760 & 1250 & $\begin{array}{l}1200 \\
(1580)\end{array}$ & $1400(?)$ \\
\hline Melting point ( $k$ ) & 1690 & 1510 & 1740 & $\begin{array}{l}\text { Sublimes } \\
>2100\end{array}$ & $\begin{array}{l}\text { Phose } \\
\text { chonge }\end{array}$ \\
\hline Physicel stcbility & Good & Foir & Feir & Excellent & very good \\
\hline $\begin{array}{l}\text { Electron mobitity } \\
\text { R.T. cm } \mathrm{cm}^{2} / \mathrm{v}-5 \\
\end{array}$ & 1400 & 8500 & 350 & $\begin{array}{r}1000 \\
(600) \\
\end{array}$ & 2200 \\
\hline $\begin{array}{l}\text { Hole mobility } \\
\text { R.T., } \mathrm{cm}^{2} / \mathrm{V}-\mathrm{s}\end{array}$ & 600 & 400 & 100 & 40 & 1500 \\
\hline $\begin{array}{l}\text { 8reokdown volloge } \\
E_{b} \cdot 105 \mathrm{~V} / \mathrm{cm}\end{array}$ & .3 & .4 & - & 4 & 10 \\
\hline $\begin{array}{l}\text { Thermel conductivity } \\
a, W / \mathrm{cm}-\mathrm{C}\end{array}$ & 1.5 & .5 & .8 & 5 & 20 \\
\hline $\begin{array}{l}\text { Sot. elec. drift vel. } \\
\text { v(sot }) .10^{7} \mathrm{~cm} / \mathrm{s}\end{array}$ & 1 & 2 & - & 2.5 & 2.7 \\
\hline Dielectric const., $\mathrm{K}$ & 11.8 & 12.8 & 11.1 & 9.7 & 5.5 \\
\hline Relotive $2 \mathrm{~J}$ & 1 & 7 & - & 1100 & 8100 \\
\hline Relotive $Z_{K}$ & 1 & .5 & - & 6 & 32 \\
\hline
\end{tabular}

ORIGINAL PAGE IS OF POOR QUALTY

excellent and its stability in an oxidizing atmosphere gives it an edge over diamond. We believe that long term stability at high temperatures will be a problem with the more common III-V compounds, such as GaAs and GaP. Thus, Sic has a significant advantage where long-term reliable operation is a requirement. For high temperature power applications, the advantages of sic and diamond are illustrated by their much higher values of breakdown electric field and thermal conductivity. Another potential area of application for sic (and diamond) is high frequency. Two Figures of Merit of semiconductors for high frequency applications are the Johnson $\left(z_{j}\right)$ and Keyes $\left(z_{K}\right)$. Relative values (to that of $\mathrm{Si}$ ) for these quantities illustrate the high potential of SiC and diamond. While sic is advancing rapidly, the difficulty of diamond crystal growth casts doubt over its near-term commercial semiconductor development.

\section{CRYSTAL GROWTE}

An essential element of a viable sic semiconductor device technology is the availability of large-area substrates on which to grow single-crystal sic films for device fabrication. For many years, the only substrates available were small irregular-shaped Sic crystals that were grown by a sublimation process, known as the Lely process. During the 1980s, much progress was made in growing single-crystal 3c-sic films on single-crystal si substrates (Nishino et al. 1983). But the 208 lattice mismatch between $\mathrm{SiC}$ and $S i$ resulted in a large defect density in the sic films, making the films unguitable for device fabrication. A process, known as the modified 
sublimation process, has been developed to grow large single-crystal sic boules from which wafers can be sliced. In Fig. 1, a $6 \mathrm{H}-\mathrm{SiC}$ wafer (grown by Cree Research, Inc.) illustrates the extent of improvement over the small Lely-grown crystals. The following sections describe sic boule and epitaxial film growth processes.

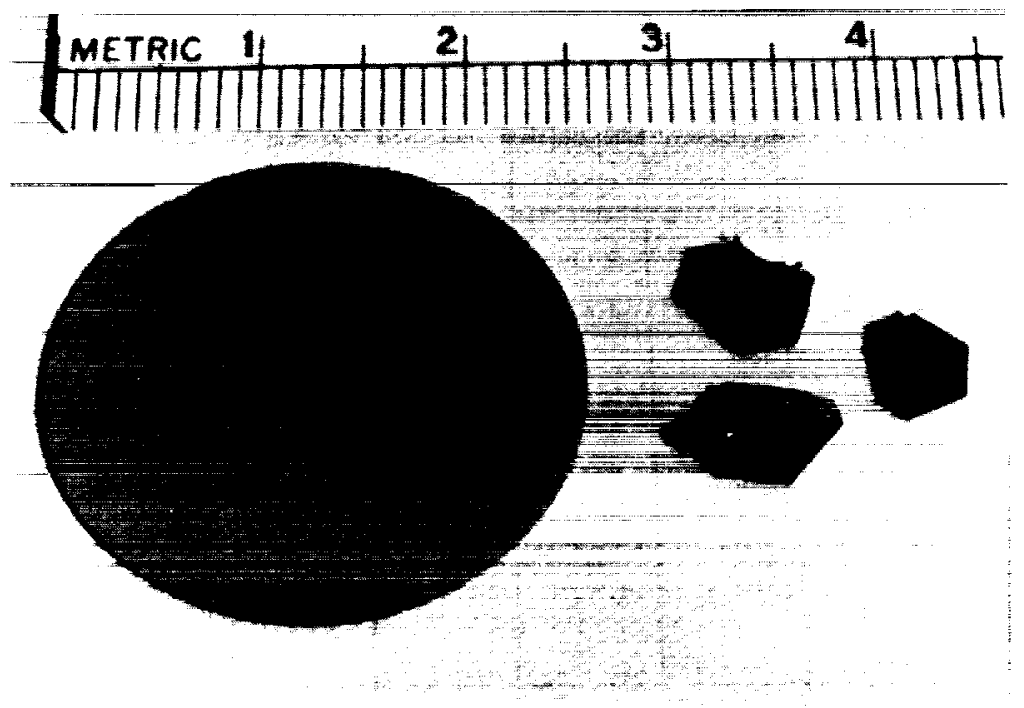

FIGURE 1 .

Left: $6 \mathrm{H}-\mathrm{SiC}$ Wafer Obtained from Cree Research, Inc.

Right: Typical LelyGrown 6H-SiC Crystals

\section{Boule Growth}

The modified sublimation process for growing SiC boules was pioneered by Tairov and Tsvetkov (1978) in Russia. In this process, nucleation takes place on a Sic seed crystal located at one end of a cylindrical growth cavity. A temperature gradient is established within the cavity such that the polycrystalline SiC is at $2700 \mathrm{~K}$ and the seed crystal is at $2500 \mathrm{~K}$. At these temperatures SiC sublimes from the polycrystalline material and condenses on the cooler seed crystal. Growth takes place on the seed crystal in an atmosphere of argon at $200 \mathrm{~Pa}$. Boules of single polytype $6 \mathrm{H}-\mathrm{SiC}$ can be grown with growth rates up to $4 \mathrm{~mm} / \mathrm{h}$ and sizes greater than $25 \mathrm{~mm}$ in diameter and 20 $\mathrm{mm}$ long. This process is now also being used by groups in the U. S., Germany, and Japan.

\section{Epitaxial Film Growth}

Although a variety of epitaxial growth processes has been used to produce siC films on SiC substrates, we believe that the most promising is the CVD process; hence, we discuss only this process in this paper.

At a CVD growth temperature of $1750 \mathrm{~K}$, the orientation of the $6 \mathrm{H}-\mathrm{SiC}$ substrate determines the polytype of the grown film. If the growth surface is within about $1^{\circ}$ of the $(0001)$ plane, then a 3C-Sic film will form, if the angle is greater than $1.5^{\circ}$, then $6 \mathrm{H}-\mathrm{SiC}$ will form (Matsunami 1989). Generally, $6 \mathrm{H}-\mathrm{SiC}$ substrates with tilt angles of $3^{\circ}$ to $4^{\circ}$ are used to grow $6 \mathrm{H}-\mathrm{SiC}$ films.

In the NASA CVD growth (Powell 1990), substrates were cut from $3.5^{\circ} 6 \mathrm{H}-\mathrm{SiC}$ wafers obtained from Cree Research, Inc. The CVD system utilized a watercooled horizontal growth chamber operating at atmospheric pressure. The carrier gas was hydrogen, and the sources of $S i$ and $C$ were silane and propane, 
respectively. After an initial etch of the SiC substrate with hydrogen chloride at $1450 \mathrm{~K}$, the substrate temperature was increased to $1730 \mathrm{~K}$ for $\mathrm{film}$ growth. Typically, a $4-\mu \mathrm{m} / \mathrm{hr}$ growth rate was achieved for the $6 \mathrm{H}-\mathrm{sic}$ films.

\section{DEVICE TECHNOLOGY}

Much Sic device technology has been developed over the last several decades and much can be borrowed from Si technology. To fabricate devices, a variety of processes are used to introduce controlled amounts of dopants (i.e. donors and acceptors), and to oxidize, etch, and metallize the material. This section reviews some of these processes and describes two sic devices, a $p-n$ junction diode and a MOSFET, that were fabricated at NASA Lewis.

\section{Controlled Doping}

Either AI or $B$ can be used as p-type dopants in SiC, but Al is preferred because its ionization energy is less (257 mev vs $735 \mathrm{meV}$ in $3 \mathrm{C}-\mathrm{SiC}$ ). Nitrogen is electrically active in SiC and is preferred as the n-type dopant because of its high solubility and relatively low ionization energy (54 mev in $3 \mathrm{C}-\mathrm{SiC}$ ). These dopants can be introduced during CVD growth.

In commercial si technology, diffusion and ion implantation are the key processes used to introduce dopants during device fabrication. Diffusion is not practical with SiC because diffusion coefficients are negligible below $2100 \mathrm{~K}$. In fact this is one of the strengths of SiC; dopants don't move at elevated temperatures. Ion implantation has been successfully applied to Sic. Recent work by Edmond et al. (1987) demonstrated that implanting at high temperatures (approx. $800 \mathrm{~K}$ ), followed by annealing at $1500 \mathrm{k}$, resulted in improved structural and electrical properties.

\section{Oxidation, Etching, and Metallization}

Silicon carbide can be oxidized similar to $\mathrm{Si}$. The oxide can be used for insulation, passivation, and as masks for ion implantation. Also, thermal oxidation has been used successfully to produce the gate dielectric in the fabrication of SiC field-effect transistors (FETs).

During device fabrication, etching processes for removing portions of the semiconductor are required. In the past, molten salts and gases (e.g. $\mathrm{Cl}_{2} / \mathrm{O}_{2}$ mixture) at high temperatures served as etchants for Sic. Recently reactive ion etching (RIE) has been used very successfully for Sic. Clean RIE-etched Sic surfaces with a high degree of anisotropic etching can be achieved.

Since a major use of sic devices will probably be in high temperature environments, the development of suitable metallization for electrical contacts is crucial. Below $700 \mathrm{~K}$, the problem may not be very difficult... An. alloy of Au with a few percent of $T a$ has been used for $n-t y p e$, and $A l$ has been used for p-type at these temperatures. At higher temperatures, a multi-layer structure will probably be required. The goal of the various layers will be to provide an ohmic contact, while also providing a diffusion barrier to prevent intermixing of materialg. Various metal carbides and silicides are being invegtigated. 


\section{P-N Junction Diode}

The first high-temperature prototype sic device fabricated at NASA Lewis was a $p-n$ junction diode. The junction structure was produced by first growing a nitrogen-doped n-type $6 \mathrm{H}-\mathrm{SiC}$ film followed by an aluminum-doped p-type film. Photolithography and RIE were used to fabricate an array of mesa diodes. After passivating the junction boundary with $\mathrm{SiO}_{2}$, metal contacts were then applied to the $p$ and $n$ regions. Excellent diode characteristics were observed up to $870 \mathrm{~K}$, the highest temperature measured, as shown in Fig 2. The forward voltage drop at room temperature for 20 ma was 12 volts, but decreased to 3.4 volts at $870 \mathrm{~K}$. The leakage current at -300 volts was $48 \mu \mathrm{a}$ at $870 \mathrm{~K}$.
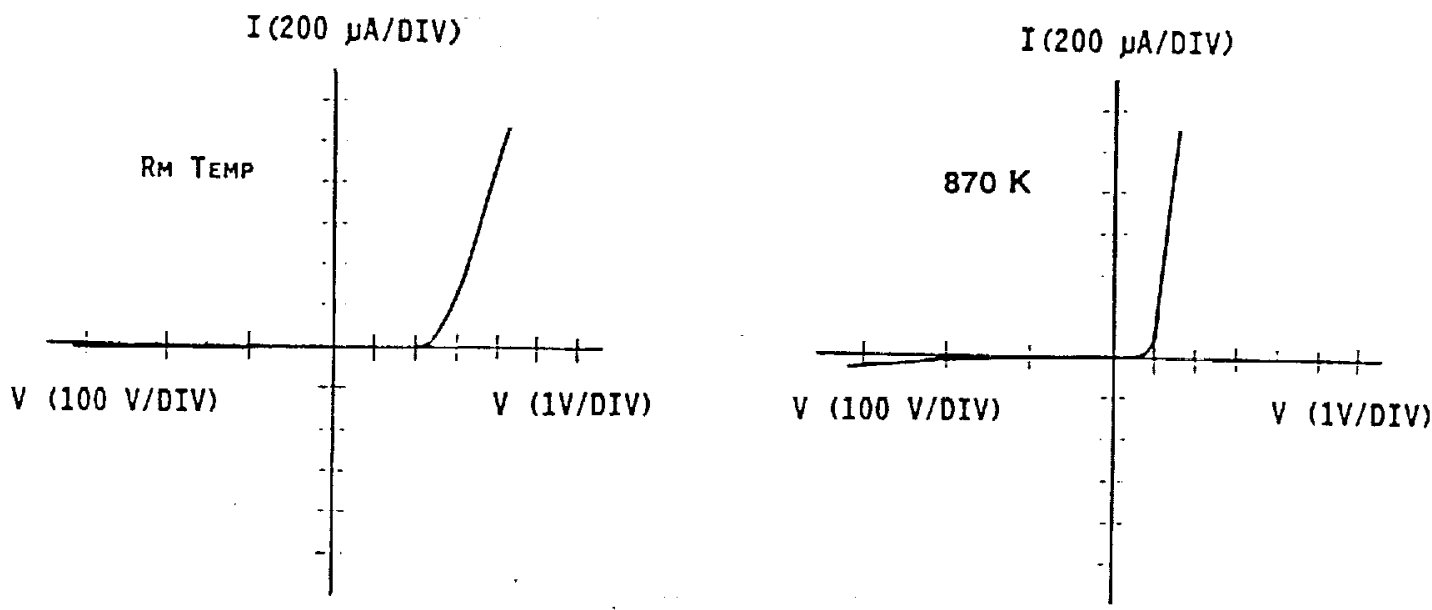

FIGURE 2. current-Voltage (I-V) Curves for a 6H-SiC Junction Diode.

\section{MOSFET}

Another prototype SiC device fabricated at NASA Lewis was a MOSFET. For this device, the sequence of $6 \mathrm{H}-\mathrm{SiC}$ films grown on the 6H-SiC substrate consisted of (1) an n-type buffer layer, (2) a p-type isolation layer, and (3) a 0.7$\mu m-t h i c k$ n-type channel layer. An array of MosfeTs were then fabricated frcm this structure using many additional steps that included photolithography, oxidation, and metalization. The source-drain I-V curves of one of the MOSFETs are given in Fig. 3. An excellent characteristic of the curves is that the saturated room-temperature drain currents are horizontal out to 100 volts. The early stage of development of this device is illustrated by some characteristics of the curves. For example, the non-1inear I-V behavior near the origin is most Iikely due to non-ohmic contacts. Also, the MosFET does not shut off with 20 volts applied to the gate. The effect is greater at $770 \mathrm{~K}$ as expected. This is probably due to non-optimized oxide and channel thicknesses.

\section{CONCLUSIONS}

Silicon carbide semiconductor technology was just a promise for many years, but has accelerated rapidly over the last several years. The devices fabricated at NASA Lewis and elsewhere demonstrate that excellent performance can be achieved. We want to emphasize that much development and optimization remain. However, we believe that sic can be an enabling electronic technology for many of the ambitious plans that man has for both earth and space. 

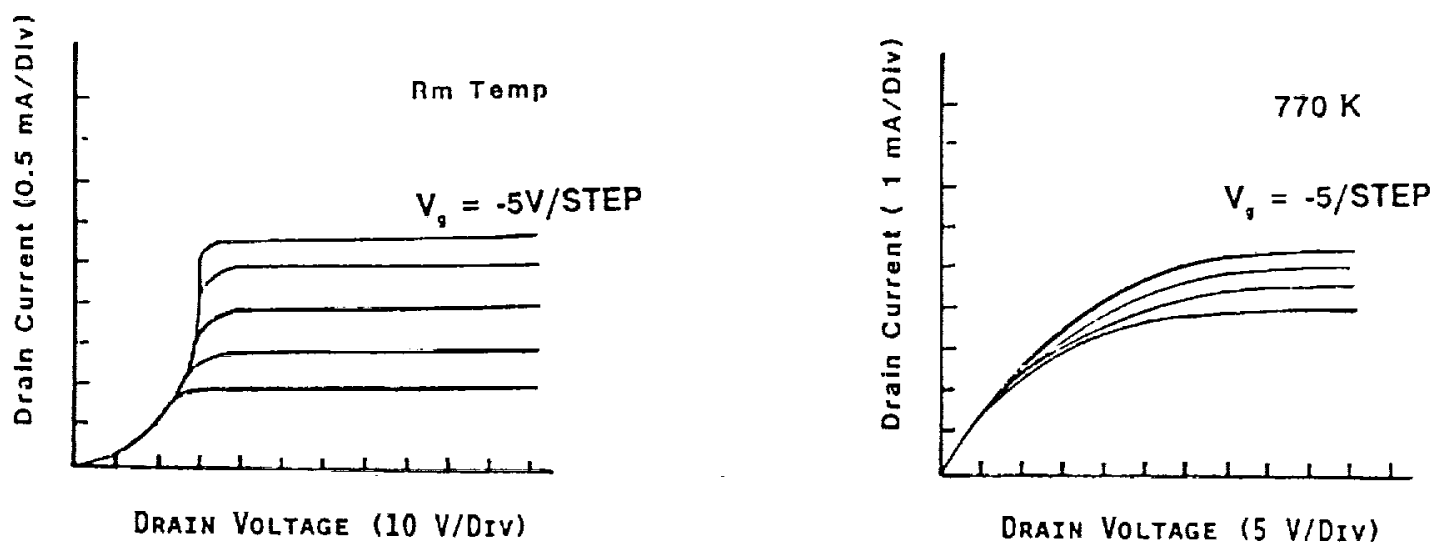

FIGURE 3. Source-Drain Current voltage (I-V) Curves for a $6 \mathrm{H}-\mathrm{SiC}$ DepletionMode MOSFET. Note Change in Horizontal Scale.

\section{Acknowledgments}

The work described herein was performed at the NASA Lewis Research Center under internal funding support.

\section{References}

Edmond, J. A., S. P. Withrow, W. Wadlin and R. F. Davis (1987) in Proc. Mats. Res. Soc. Symp., Vol. 77, 193.

Harris, G. I. and C. Y.-W. Yang, eds. (1989) Amorphous and Crystalline Silicon Carbide, springer Proceedings in Physics, Vol. 34, Springer-Verlag, Heidelberg.

Matsunami, H., K. Shibahara, N. Kuroda, and S. Nishino (1989) in Amorphous and Crystalline silicon Carbide, Springer Proceedings in Physics, Vol. 34, G. L. Harris and C. Y.-W. Yang, eds., Springer-Verlag, Heidelberg.

Nishino, S., J. A. Powell, and H. A. Will (1983) "Production of Large-Area Single-Crystal Wafers of Cubic sic for Semiconductor Devices," Appl. Phys. Lett., 42(5): 460-462.

Powell, J. A. et al. (1990) "Growth of High Quality 6H-SiC Epitaxial Films on Vicinal (0001) 6H-SiC Wafers," Appl. Phys. Lett., 56(15): 1442-1444.

Tairov, Y. M. and V. F. Tsvetkov (1978) "Investigation of Growth Processes of Ingots of Silicon Carbide Single Crystals," J. Cryst. Growth, 43: 209-212. 


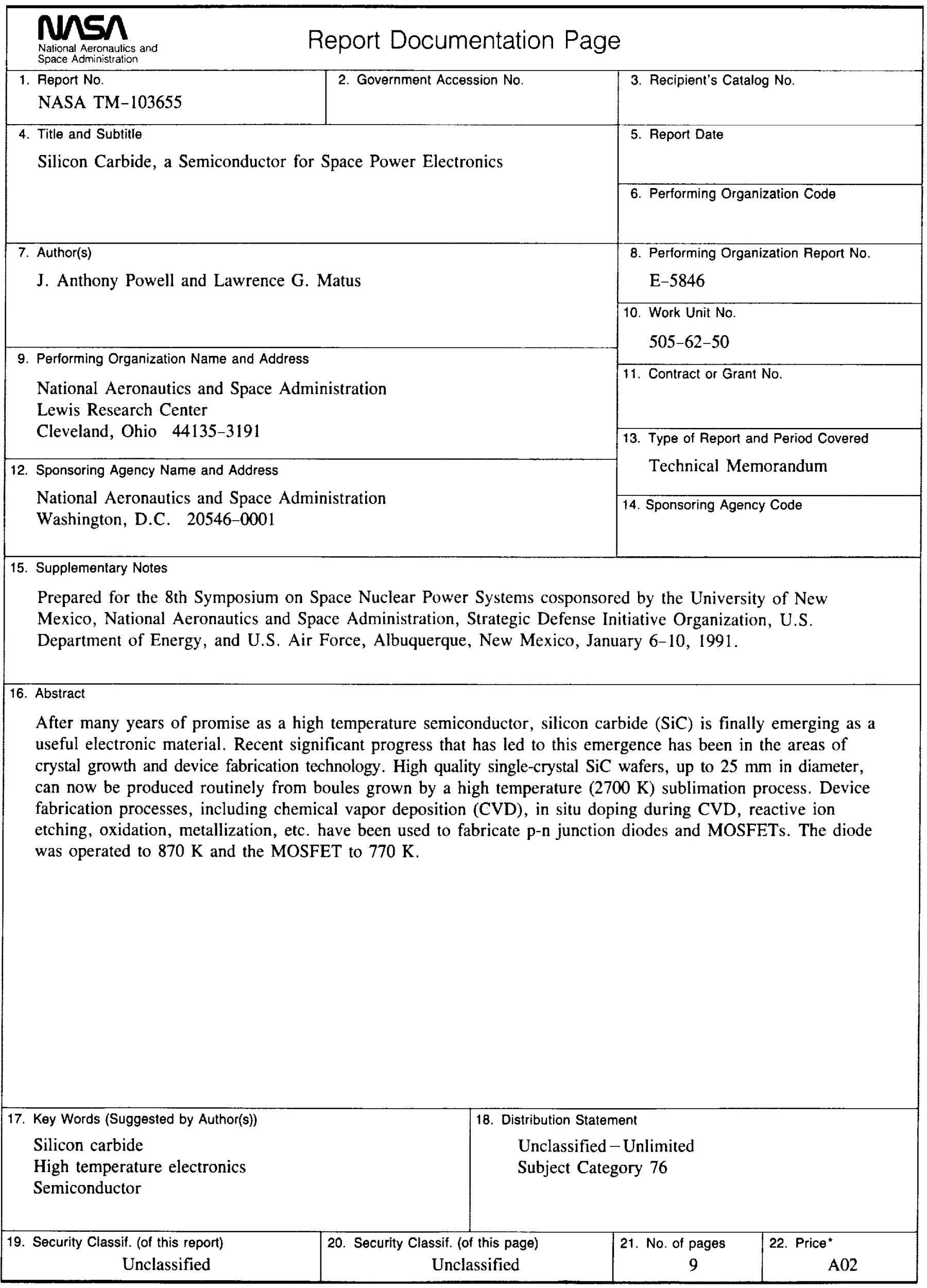


